\title{
Intramammary administration of platelet concentrate as an unconventional therapy in bovine mastitis: First clinical application
}

\author{
A. Lange-Consiglio, ${ }^{*}$ C. Spelta, ${ }^{*}$ R. Garlappi, $†$ M. Luini, $\ddagger$ and F. Cremonesi ${ }^{*}{ }^{1}$ \\ *Large Animal Hospital, Reproduction Unit, Università degli Studi di Milano, 26900 Lodi, Italy \\ †Private practitioner, 26833 Comazzo, Lodi, Italy \\ łlstituto Zooprofilattico Sperimentale della Lombardia e dell'Emilia Romagna, 26900 Lodi, Italy \\ §Department of Veterinary Science for Animal Health, Production and Food Safety, Università degli Studi di Milano, 20133 Milano, Italy
}

\begin{abstract}
Bovine udder infections induce a variety of changes in gene expression of different growth factors that may suggest their possible role in glandular tissue protection or repair processes. Growth factors and also chemokines and cytokines may act synergistically to increase the infiltration of neutrophils and macrophages to promote angiogenesis, fibroplasia, matrix deposition, and, ultimately, re-epithelialization. Considering the vast applications, typically in human medicine, of platelet concentrate (PC) and its ease of preparation, the aim of our study was to evaluate an alternative therapy to stimulate the regeneration of glandular tissue, administering a concentration in excess of the growth factors contained in the PC. In each one of the 3 farms examined in the trial, $\mathrm{PC}$ was prepared from donor cows in good health, free from infections, and with no records of medications administered during the previous 2 mo. The platelet produced in one farm was used only for treating the cows of the same farm in a heterologous way. A total of 229 mastitic quarters were divided in 3 groups: antibiotic group (treated with intramammary antibiotic), antibiotic and PC group (treated intramammarily with antibiotics in association with $\mathrm{PC}$ ), and PC group (treated with intramammary PC alone). The diagnosis of mastitis was based on somatic cell count and bacteriological evaluation of the milk from the affected quarter. Platelet concentrate, alone or in association with antibiotic, was used for 3 consecutive days as an unconventional therapy in bovine acute and chronic mastitis. Our data show that the associated action of antibiotic and PC performed significantly better than the antibiotic alone, either for the recovery of the affected mammary quarters or for somatic cell count reduction. In the same way, the association antibiotic plus PC showed significantly fewer relapses compared with the antibiotic alone, either for acute
\end{abstract}

Received January 30, 2014.

Accepted June 26, 2014.

${ }^{1}$ Corresponding author: fausto.cremonesi@unimi.it or chronic mastitis. The treatment with only PC did not show statistically significant differences compared with both antibiotic alone or associated treatment for acute mastitis, and it was better than the use of only antibiotic for chronic mastitis. Our results show that PC alone may be useful for a quick resolution of the inflammatory response, playing a role in limiting the tissue damage to the mammary gland parenchyma and reducing the recurrence rates.

Key words: platelet concentrate, mastitis, growth factor, antibiotic, relapse

\section{INTRODUCTION}

An effective mastitis control program should be based on the containment of new infections through correct milking management, careful aseptic practices, and reducing the duration of existing infections with lactation antibiotic therapies, dry cow therapy, and by culling of refractory animals. For these reasons, mastitis is the most costly infectious disease of dairy cattle. Indeed, in addition to decreased production, economic losses associated with clinical mastitis include cost of treatment, extra labor, and an increased rate of cow replacement (Bartlett et al., 1990). Although antibiotics are very useful to treat infections, they do not directly protect the gland from being damaged (Zhao and Lacasse, 2008). Moreover, mastitis, besides being an animal welfare issue, is also a food safety problem because it should be taken into account that dairy cows produce milk for human consumption. This assumption makes urgent to expand the prophylaxis interventions based on management, livestock hygiene, respect for animal welfare, and the development of alternative remedies that can replace or support those currently in use. In addition to the use of antibiotics, other therapies, aimed at reducing udder tissue damages, may be a cost-effective way to reduce the losses caused by mastitis (Zhao and Lacasse, 2008).

Studies performed in organic farms, which represent only a small part of dairy farming, show that in Germa- 
ny and the United Kingdom 34 and 51\%, respectively, of clinical mastitis cases were treated with homeopathic remedies (Hovi and Roderick, 2000; Krömker and Pfannenschmidt, 2005). So far, only a few papers on the use of homeopathy as a treatment strategy against mastitis have been published, mainly because many of these studies have often been criticized for their inadequate scientific approach (Cucherat et al. 2000).

Werner et al. (2010) showed a therapeutic effect of homeopathic treatment only in cases of mild and moderate clinical mastitis that were caused by environmental pathogens or those with no provable pathogen in the milk sample at $\mathrm{d} 0$. Therefore, exclusion of mastitis caused by udder-associated pathogens in the dairy herd in combination with an improved farmand cow-specific diagnostic procedure is an important precondition when using the homeopathic treatment strategy. For this reason, it would be important to identify alternatives to the use of antibiotics, especially knowing that mastitis induces disruption of the normal secretory functions of the mammary gland by reducing the number of epithelial cells and their activity. Mammary epithelial cells are able to produce a variety of inflammatory mediators such as cytokines, chemokines, host-defense peptides, and arachidonic acid metabolites (Sharma et al., 2011). An array of immunoregulatory cytokines are likely involved in mediating the immune responses to mastitis and have been proposed as potential preventives for mastitis (Blecha, 1991; Kehrli et al., 1991). Indeed, infection of bovine udders induces a variety of changes in gene expression, including a decrease in $\alpha$-LA and casein mRNA and, on the contrary, an increase in mRNA of several growth factors, including acidic fibroblast growth factor, basic fibroblast growth factor, epidermal growth factor, transforming growth factor (TGF) $\alpha$, IGF-I, and IGF-II. These results suggest a possible role of peptide growth factors in tissue protection or repair processes (Sheffield, 1997). For this reason, a different approach for the treatment of mastitis might be to stimulate the regeneration of glandular tissue, providing a supraphysiological concentration of growth factors through the use of platelet concentrate (PC) as an alternative therapy. Platelets, in fact, contain a significant amount of growth factors, accumulated in their $\alpha$-granules, which may be useful in the healing process. Transforming growth factor $\beta 1$ and TGF- $\beta 2$, the platelet-derived growth factors (PDGF; PDGF-AA, PDGF-BB, and PDGF-AB), IGF-I, epidermal growth factor, and hepatocyte growth factor are very important for the healing process. Platelets secrete growth factors and also chemokines and cytokines and release active metabolites, each of which could have a positive influence in clinical situations requiring rapid healing and tissue regeneration. Indeed, these growth factors act synergistically to increase the infiltration of neutrophils and macrophages, and to promote angiogenesis, fibroplasia, matrix deposition, and, ultimately, re-epithelialization (Anitua et al., 2004).

Because several in vitro studies have shown a direct dose-response influence of many growth factors on cell migration, cell proliferation, and matrix synthesis (Abrahamsson, 1997; Thomopoulos, 2005; Costa et al., 2006; Haupt et al., 2006), it has been suggested that the local administration of increased concentrations of these growth factors through the use of PC could optimize the local healing environment and thus enhance the ability of biologically compromised tissues to generate a repair response (Marx, 2004).

In human medicine, maxillofacial surgery, dental implant surgery, orthopedic surgery and bone reconstruction, muscle and tendon repair, reversal of skin ulcers, retinal hole repair in eye surgery, and cosmetic surgery are situations where autologous platelet concentrate accelerate healing (Anitua et al., 2004). In veterinary medicine, little clinical information exists about the application of platelet-rich plasma. It is mainly used for equine tendon repair (Georg et al., 2010) and its application has also been reported on intestinal wound healing in pigs (Fresno et al., 2010) and on a large cutaneous lesion in a dog (Kim et al., 2009).

In these circumstances, it seemed interesting to carry out a study based on the concept of regenerative medicine for the control of bovine mastitis by the use of PC. Considering the efficacy of PC mostly in human medicine, the absence of reports in the scientific literature on the use of $\mathrm{PC}$ in bovine mastitis, and its ease of preparation, the aim of our study was to evaluate the effect of PC administration, alone or associated with antibiotic therapy, in the control of clinical acute and chronic mastitis.

\section{MATERIALS AND METHODS}

\section{Experimental Design}

The study was performed between January and April 2012, which is supposed to be the most stable climatic period in Italy, with a low rain rate and temperature between 0 and $10^{\circ} \mathrm{C}$.

Farms. The experiment was carried out in 3 farms managed in a cubicle yard and divided into different lactation groups. Herd size varied from 150 to 300 cows in lactation. One herd was managed by milking robots, whereas the other 2 followed a twice-daily milking regimen. Cows suffering from mastitis were identified at milking time by the farmer or by the robot control pro- 
gram. Mastitis diagnosis was subsequently confirmed by the veterinarian enrolled in the study for examining the cows for inclusion in the trial.

Mastitis Diagnosis. The careful diagnosis of mastitis took into account the changes in the milk (chunks, flakes, clots, or blood), the changes in the condition of the affected quarter (swelling, redness, hardening, heat, or pain), and the general condition of the animals. Depending on symptoms and milk analysis, acute and chronic mastitis were diagnosed. Acute mastitis is characterized by visible signs, such as abnormal milk (flakes, clots, decrease in milk production, and sometimes milk discoloration) and hot, swollen, and painful quarters. Milk production decreases and the milk composition is considerably altered (Harmon, 1994). Chronic mastitis is described as repeated cases of mastitis where the cow fails to respond successfully to treatment, although clinical symptoms may disappear temporarily (Akers, 2002). In our study, cows were considered affected by chronic mastitis when the SCC was $>500,000$ cells $/ \mathrm{mL}$ for 3 consecutive months (Rahman et al., 2012) in a quarter-milk sample. Cows needing general antibiotic treatments were excluded from this study.

Animals. A total of 229 animals were enrolled in this study. On each farm, cows that fulfilled the inclusion criteria were randomly allocated into 3 groups: (1) antibiotic (control) group (66 quarters), which was treated with intramammary antibiotic; (2) antibiotic and PC group (80 quarters), which was treated with intramammary antibiotics in combination with $\mathrm{PC}$ (associated treatment); or (3) PC group (83 quarters), which was treated with $\mathrm{PC}$ alone. Each mastitic udder quarter was enrolled only once.

\section{Preparation of Platelet Concentrate}

Collection of Blood. Because it takes time for PC preparation and to have the prescribed amount of $\mathrm{PC}$ immediately available for treatment as soon as a mastitis case was diagnosed, a stock of PC was prepared and kept separated for each one of the 3 farms involved in the experiment. In this way, the PC obtained from blood donor cows, in good health, free from infections and without any medication during the previous 2 mo, was used in a heterologous way for treating only the mastitic cows belonging to the same farm of the blood donor cows.

After surgical scrub preparation of a few centimeters of skin around the subcutaneous mammary vein, 450 $\mathrm{mL}$ of blood was collected in ad hoc Terumo blood bags (Terumo Srl, Rome, Italy) containing citrate-phosphatedextrose-adenine (CPDA-1) using the 16-gauge needle provided with the bags. The bags were transported at $+4^{\circ} \mathrm{C}$ to the laboratory within $2 \mathrm{~h}$ of collection and immediately processed.

Double Centrifugation Method. All separation steps were performed under a horizontal laminar flow hood in aseptic conditions. To prepare the PC, the blood was drawn into sterile Falcon tubes of $50 \mathrm{~mL}$ each (EuroClone SpA, Milan, Italy). The tubes were centrifuged at $100 \times g$ for $30 \mathrm{~min}$ at $4^{\circ} \mathrm{C}$. This caused separation of the blood into 3 components: red blood cells at the lowest level, "buffy coat" in the middle layer, and platelet-rich plasma (PRP) in the upper layer. Afterward, the PRP was carefully aspirated and distributed in new 50-mL tubes and centrifuged again at $1,500 \times \mathrm{g}$ for $10 \mathrm{~min}$ at $4^{\circ} \mathrm{C}$ to obtain the platelet pellet and the poor platelet plasma (PPP) at the upper layer. Afterward, two-thirds of the volume of PPP was aspirated for later use and the pellet mixed in the residual PPP volume to allow for platelet count before the final dilution with PPP to obtain PC at a standard concentration of $1 \times 10^{9}$ platelet $/ \mathrm{mL}$. All platelet counts on peripheral blood, PRP, and PC were performed using a HeCo Vet automatic hematology analyzer (SEAC, Florence, Italy).

The total amount of PC obtained for each donor was aliquoted in $5 \mathrm{~mL}$ ready-to-use doses that were stored in syringes. The syringes were then frozen at $-80^{\circ} \mathrm{C}$ and thawed at $37^{\circ} \mathrm{C} 3$ times (Zimmermann et al., 2003) to allow the release of platelet-derived factors. The PC was subjected to bacteriological examination to verify its sterility. Syringes containing the PC dose were kept frozen at $-20^{\circ} \mathrm{C}$ until use.

\section{Indicators of Udder Inflammation}

$S C \boldsymbol{C}$. Somatic cell count was performed starting at d 0, and then at d 7, 14, and 30 of treatment. Somatic cell counts were assessed by fluorometric measurement on a DeLaval Cell counter (DeLaval International AB, Tumba, Sweden) following International Dairy Federation procedures (IDF, 1995). The SCC is expressed as a linear score (LS), which is a logarithmic function that transforms the number of somatic cells into a linear scale:

$$
\mathrm{LS}=\log _{2}(\text { no. of cells: } 100)+3 .
$$

Bacteriological Analysis. Quarter milk samples for bacteriological assays were collected before milking using an aseptic procedure at the start of the treatment (d 0) from each affected quarter. Bacteriological analyses were performed by plating on blood agar with esculin and Baird-Parker rabbit plasma fibrinogen (RPF) agar. After incubation at $37^{\circ} \mathrm{C}$ for $48 \mathrm{~h}$, the colonies grown 
in pure culture were identified by conventional bacteriological methods on the basis of morphological and biochemical characteristics by routine methods according to the National Mastitis Council (1999).

\section{Intramammary Administration of Antibiotics and Platelet Concentrate}

All herd milking procedures included premilking cleaning of the teats with detergent and single-use paper towels and teat dipping at the end of milking with an approved teat disinfectant. All cows were treated after milking as hereafter described. After thawing, the syringe in which $\mathrm{PC}$ was stored was connected to a sterile disposable teat cannula to help the intramammary inoculation of $\mathrm{PC}$ through the teat canal. The antibiotic for local use, chosen on the basis of an antibiogram test, was inoculated using the same procedure, according to manufacturer indications. Following inoculation, the udder was gently rubbed with upward movement of the hands to distribute the product. In the case of treatment of antibiotic and PC, the latter was administered first.

After a preliminary study with different doses of PC $(5,10$, and $20 \mathrm{~mL})$, no significant differences were detected in the results (data not shown), so we decided to perform this study with $5 \mathrm{~mL}$ of PC. Five milliliters of PC alone or associated with antibiotic or antibiotic alone was administrated for 3 consecutive days, depending on the treatment group. After these treatments, teat dipping was performed.

\section{Classification of Outcomes}

Treatment outcomes were assessed by clinical and laboratory evaluations. Clinical improvement was defined as the return of quarter and milk secretion to normal. It was assessed by visual observation of milk composition and palpation of the udder. Rate of relapse was, furthermore, evaluated. A relapse was defined as a clinical mastitis event that occurred in the enrolled quarter from the last time of examination (30 d after the treatment) until the end of the same lactation. Good improvement of an udder quarter was defined as having clinically progressed and showing, at the time of last examination, an SCC value decreasing by at least 3 LS points compared with the starting value at time 0 .

\section{Statistical Analysis}

The collection efficiency of platelets for each PC obtained by double centrifugation tube methods was analyzed using the following formula (Weibrich et al., 2005): efficiency for platelet collection $=$ platelet count $/ \mu \mathrm{L}$ in $\mathrm{PC} \times$ volume of $\mathrm{PC}$

platelet count in whole blood $/ \mu \mathrm{L} \times$ volume of whole blood

Data were collected in a database and analyzed by the general linear model for repeated measures on GraphPad InStat 3.00 for Windows software (GraphPad Software Inc., La Jolla, CA). The between-subjects factor was represented by treatments (3 levels) and the within-subjects factor was represented by sampling time (4 levels) and the model applied was a full factorial, with polynomial contrasts for within-subjects factor. The statistical analysis of bacteriological data and rate of relapses was conducted using the Fisher exact test. For all tests, differences were considered statistically significant at $P \leq 0.05$.

\section{RESULTS}

\section{Platelet Collection Efficiency}

The platelet collection efficiency for the PC obtained by the double centrifugation protocol was (mean $\pm \mathrm{SD}$ ) $10.9 \pm 2.3 \%$, indicating that $10.9 \pm 2.3 \mathrm{~mL}$ of PC at the concentration of $1 \times 10^{9}$ platelet $/ \mathrm{mL}$ was obtained from $100 \mathrm{~mL}$ of blood.

\section{SCC and Bacteriological Assay}

Of the 229 cows in our study, 144 were classified as affected by acute mastitis and 85 by chronic mastitis. At time 0 , the average value of SCC was $11 \times 10^{6}$ cells/ $\mathrm{mL}$ with a standard deviation of $4.4 \times 10^{6}$ cells $/ \mathrm{mL}$ in acute mastitis and $6.14 \times 10^{6}$ cells $/ \mathrm{mL}$ with a standard deviation of $6.0 \times 10^{6}$ cells $/ \mathrm{mL}$ in chronic mastitis.

The allocation of the enrolled quarters into the 3 different experimental groups was performed randomly at the treatment start before the results of the bacteriological assays. With the exception of the esculin-positive streptococci group, which was less represented in the acute mastitis antibiotic-treated group, the distribution of the enrolled quarters positive for bacterial growth was random and not significantly different among the treatment groups either with acute or chronic mastitis, as shown in Tables 1 and 2.

\section{Treatments}

Results of the treatments with antibiotic alone, antibiotic and PC, and only PC are reported in Table 3 , which shows the percentage of quarters with an improvement of at least $3 \mathrm{LS}$ points less than the start- 
Table 1. Allocation of enrolled quarters with acute mastitis positive to bacterial growth into 3 experimental groups

\begin{tabular}{lcccc}
\hline & & \multicolumn{3}{c}{ Treatment [no. (\%)] } \\
\cline { 4 - 5 } Item & $\begin{array}{c}\text { Total no. of } \\
\text { quarters (\%) }\end{array}$ & Antibiotic & Antibiotic and PC ${ }^{\mathrm{a}}$ & PC \\
\hline Quarters & & & & \\
$\quad$ Total treated & $144(100)$ & $40(27.78)$ & $53(36.80)$ & $51(35.42)$ \\
Positive to bacterial growth & $91(63.19)$ & $25 / 40(62.5)^{\mathrm{a}}$ & $38 / 53(71.7)^{\mathrm{a}}$ & $28 / 51(54.9)^{\mathrm{a}}$ \\
Microorganism & & & & \\
Esculin-positive streptococci & $37 / 91(40.66)$ & $5(14)^{\mathrm{a}}$ & $17(46)^{\mathrm{b}}$ & $15(40)^{\mathrm{b}}$ \\
CNS & $19 / 91(20.88)$ & $7(36.84)^{\mathrm{a}}$ & $8(42.11)^{\mathrm{a}}$ & $4(21.05)^{\mathrm{a}}$ \\
Escherichia coli & $25 / 91(27.47)$ & $9(36)^{\mathrm{a}}$ & $10(40)^{\mathrm{a}}$ & $6(24)^{\mathrm{a}}$ \\
Streptococcus dysgalactiae & $6 / 91(6.79)$ & $2(33.33)^{\mathrm{a}}$ & $1(16.67)^{\mathrm{a}}$ & $3(50)^{\mathrm{a}}$ \\
Coagulase-positive staphylococci & $2 / 91(2.2)$ & $1(50)^{\mathrm{a}}$ & $1(50)^{\mathrm{a}}$ & - \\
Enterobacteriaceae & $2 / 91(2.2)$ & $1(50)^{\mathrm{a}}$ & $1(50)^{\mathrm{a}}$ & - \\
${ }^{\mathrm{a}, \mathrm{b}}$ Different superscript letters within a row indicate significant differences $(P<0.05)$. & \\
${ }^{1}$ PC = platelet concentrate. & & &
\end{tabular}

ing value and the rate of relapse. Statistical analysis showed that the associated treatment of antibiotic and PC had significantly superior performance $(P<0.05)$ compared with antibiotic alone relative to the improvement of mammary mastitic quarters and to the rate of relapse. The treatment with PC only did not show statistically significant differences compared with both antibiotic alone and the associated treatment for the acute mastitis group, whereas it was significantly better $(P<0.05)$ than antibiotic alone for the chronic mastitis group relative to the number of improved quarters and relapses.

Table 4 shows the values and the significant differences in the SCC expressed as LS at the different time points during treatments for acute and chronic mastitis with different protocols. These data illustrate that the starting LS values of the associated treated quarters were the highest (worst) compared with the other groups and that at $30 \mathrm{~d}$ after treatment (T30), a statistically significant difference $(P<0.05)$ existed between the associated treatment group compared with the antibiotic or PC alone groups. The associated treatment, in fact, decreased the mean value of LS more significantly than other treatments, whereas the treatment with PC or antibiotic performed similarly. Moreover, either for acute or chronic mastitis, the improvement in LS values in the PC treatment group started to be evident at $\mathrm{d}$ 14 from the beginning of treatment with respect to the antibiotic alone and at $\mathrm{d} 7$ with respect to the associated groups. The final outcome of the PC treatment alone and the antibiotic treatment was similar.

\section{DISCUSSION}

The extensive use of antibiotics implies an increased risk of residues in milk and, in the common perception, the development of antibiotic resistance. However, scientific evidence does not support a widespread, emerging resistance among mastitis pathogens to antibacterial drugs, but definitive conclusions on resistance patterns of mastitis pathogens are difficult, given the limitations of the data presented in the literature (Erskine et al., 2004). The maintenance of consumer confidence, by satisfactory levels of animal welfare and restricted use of antibiotics, continues to be an important matter. In these contexts, we explored a different approach for mastitis therapy using PC as an alternative treatment. The experimental approach is based on the regenerative properties of the $\mathrm{PC}$ described in the literature (for a review, see Anitua et al., 2004).

Table 2. Allocation of enrolled quarters with chronic mastitis positive to bacterial growth into 3 experimental groups

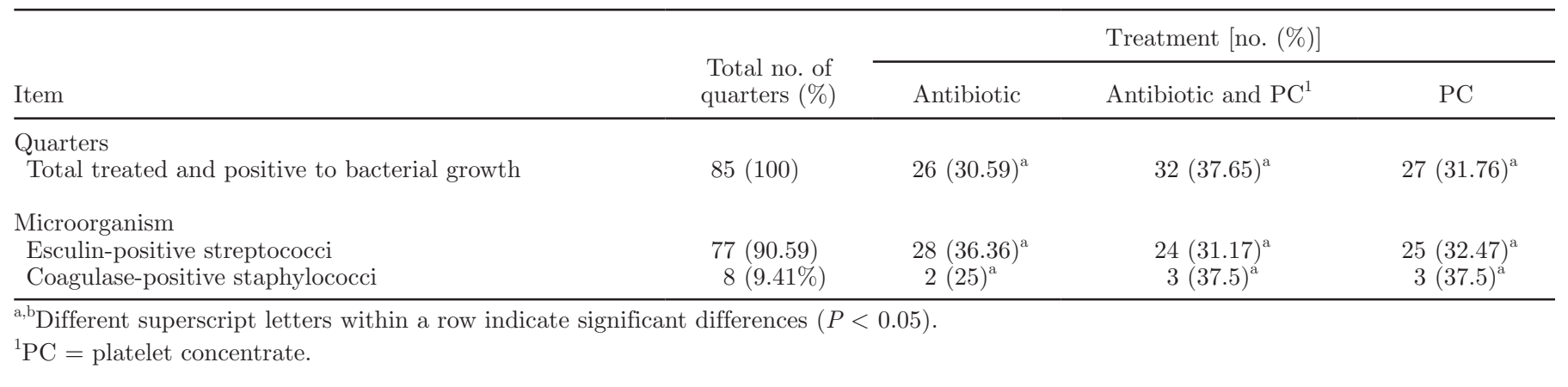


Table 3. Data relating to the improvement (decrease) in SCC and rate of relapse for each treatment, and clinical distinction between acute and chronic mastitis

\begin{tabular}{|c|c|c|c|c|c|c|}
\hline Mastitis & Treatment $^{1}$ & $\begin{array}{c}\text { No. of } \\
\text { treated } \\
\text { quarters }\end{array}$ & $\begin{array}{c}\text { Quarters with } \\
\text { improvement } \\
\text { of at least } \\
3 \text { LS points } \\
\text { [no. }(\%)]\end{array}$ & $\begin{array}{l}\text { Quarters with } \\
\text { improvement } \\
<3 \text { LS points } \\
\text { [no. }(\%)]\end{array}$ & $\begin{array}{c}\text { Relapse on quarters } \\
\text { with improvement } \\
\text { of at least } \\
3 \mathrm{LS} \text { points } \\
\text { [no. }(\%)]\end{array}$ & $\begin{array}{c}\text { Quarters with } \\
\text { improvement } \\
\text { of at least } \\
3 \text { LS points } \\
\text { without relapse } \\
\text { [no. (\%)] }\end{array}$ \\
\hline \multirow[t]{2}{*}{ Acute } & Antibiotic & 40 & $21(52.50)^{\mathrm{a}}$ & $19(47.50)^{\mathrm{a}}$ & $9(42.86)^{\mathrm{a}}$ & $12(57.14)^{\mathrm{a}}$ \\
\hline & $\mathrm{PC}$ & 51 & $34(66.67)^{\mathrm{a}}$ & $17(33.33)^{\mathrm{a}}$ & $10(29.41)^{\mathrm{a}}$ & $24(70.59)^{\mathrm{a}}$ \\
\hline Chronic & Antibiotic $+\mathrm{PC}$ & 27 & $18(66.67)^{\mathrm{B}}$ & $9(33.33)^{\mathrm{B}}$ & $2(11.11)^{\mathrm{B}}$ & $16(88.89)^{\mathrm{B}}$ \\
\hline
\end{tabular}

$\overline{\mathrm{a}, \mathrm{b}}$ Different superscript lowercase letters within a column indicate significant differences $(P<0.05)$ among treatments in acute mastitis comparisons.

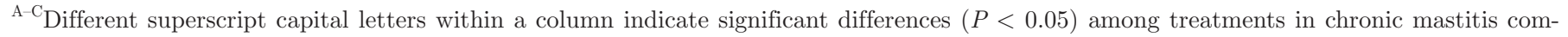
parisons.

${ }^{1} \mathrm{PC}=$ platelet concentrate.

${ }^{2} \mathrm{LS}=$ linear score.

In our study, from the random allocation into 3 groups of the enrolled quarters positive for bacterial growth, it is possible to show that the distribution of quarters with different bacterial involvement was not significantly different among treated groups, with the exception of the esculin-positive streptococci group, which was less represented in the acute mastitis group treated with antibiotic. In addition, from the analysis of the average SCC, expressed as LS, the starting LS values of the associated treated quarters were the highest. In these conditions, our results showed that in all treated groups, the average LS decreased significantly $(P \leq 0.05)$ at T30, but in the associated treatment group with acute mastitis, the average LS decreased to 2.7 points, with a value of $\mathrm{SCC}<100,000$ cells $/ \mathrm{mL}$ of milk in the quarter-milk sample. This value is in accordance with the definition of a healthy udder quarter (Carlén, 2008). In the case of acute mastitis, no statistically significant differences in the average values of LS at T30 were observed between PC-alone- or antibioticalone-treated quarters.

Furthermore, it was demonstrated that the combined action of antibiotic and PC performed significantly ( $P$ $\leq 0.05)$ better than the antibiotic alone with regard to clinical improvement of mammary quarters affected by mastitis. In the same way, the combined treatment gave significantly better results $(P \leq 0.05)$ compared with the antibiotic alone with regard to relapse. The percentage of mammary quarters that reached an improvement of at least $3 \mathrm{LS}$ points less than the starting value of SCC and did not show relapse after treatment with antibiotic and $\mathrm{PC}$ was significantly higher $(P \leq$ $0.05)$ than the quarters that reached an improvement of at least $3 \mathrm{LS}$ points and that showed relapse after treatment with the antibiotic alone. These data confirm the efficacy of the associated treatment.

Comparing the antibiotic-alone versus the $\mathrm{PC}$-alone treatments, the rate of improvement and relapse were

Table 4. Mean values of the linear scores on $\mathrm{d}$ 0, 7, 14, and 30 in acute and chronic mastitis treated with different protocols

\begin{tabular}{llrccc}
\hline Mastitis & Treatment $^{1}$ & \multicolumn{1}{c}{$\mathrm{d} 0$} & $\mathrm{~d} 7$ & $\mathrm{~d} 14$ & $\mathrm{~d} 30$ \\
\hline Acute & Antibiotic & $8.61 \pm 1.38^{\mathrm{a}, \mathrm{A}}$ & $6.06 \pm 2.50^{\mathrm{b}, \mathrm{A}}$ & $4.71 \pm 2.26^{\mathrm{c}, \mathrm{A}}$ & $4.70 \pm 1.21^{\mathrm{d}, \mathrm{A}}$ \\
& PC & $8.90 \pm 1.09^{\mathrm{a}, \mathrm{A}}$ & $7.99 \pm 1.40^{\mathrm{a}, \mathrm{B}}$ & $5.83 \pm 1.78^{\mathrm{b}, \mathrm{A}}$ & $4.38 \pm 1.21^{\mathrm{c}, \mathrm{A}}$ \\
& Antibiotic + PC & $10.04 \pm 0.87^{\mathrm{a}, \mathrm{B}}$ & $7.35 \pm 2.49^{\mathrm{a}, \mathrm{B}}$ & $5.06 \pm 2.28^{\mathrm{b}, \mathrm{A}}$ & $2.71 \pm 1.41^{\mathrm{c}, \mathrm{B}}$ \\
Chronic & Antibiotic & $8.40 \pm 0.45^{\mathrm{a}, \mathrm{A}}$ & $6.12 \pm 1.44^{\mathrm{b}, \mathrm{A}}$ & $5.30 \pm 1.98^{\mathrm{c}, \mathrm{A}}$ & $5.28 \pm 0.51^{\mathrm{d}, \mathrm{A}}$ \\
& PC & $8.34 \pm 1.59^{\mathrm{a}, \mathrm{A}}$ & $7.41 \pm 1.79^{\mathrm{a}, \mathrm{B}}$ & $6.37 \pm 1.88^{\mathrm{b}, \mathrm{A}}$ & $5.02 \pm 1.23^{\mathrm{c}, \mathrm{A}}$ \\
& Antibiotic + PC & $9.99 \pm 0.73^{\mathrm{a}, \mathrm{B}}$ & $8.05 \pm 1.10^{\mathrm{b}, \mathrm{B}}$ & $6.02 \pm 1.28^{\mathrm{c}, \mathrm{A}}$ & $4.70 \pm 0.44^{\mathrm{d}, \mathrm{B}}$ \\
\hline
\end{tabular}

$\overline{{ }^{a-d} \text { Different superscript lowercase letters within a row (within treatment) indicate significant differences }(P \leq}$ 0.05 ) on different days within type of mastitis (acute or chronic).

${ }^{\mathrm{A}, \mathrm{B}}$ Different superscript capital letters within a column (within day) indicate significant differences $(P \leq 0.05)$ among treatments within type of mastitis (acute or chronic).

${ }^{1} \mathrm{PC}=$ platelet concentrate. 
not statistically different regarding acute mastitis, but it is noteworthy that the treatment with $\mathrm{PC}$ alone was better than antibiotic alone for chronic mastitis. Particularly in the case of chronic mastitis, these findings suggest a possible role of growth factors in tissue protection or repair processes, or both (Sheffield, 1997). It is known, for example, that the action of TGF- $\alpha$ promotes tissue repair, mammary epithelial proliferation, and morphogenesis of the mammary gland (Derynck, 1992). For this reason, we supposed that an auxiliary administration of growth factors, including TGF- $\alpha$, present in PC, can enhance repair of damaged tissue. As a prolonged inflammatory response causes tissue damage, the PC, contributing to a rapid resolution of the inflammatory response, would play a vital role in limiting the damage to the host. Platelet concentrate, in fact, contains chemokines, some of which act in synergy with white blood cells, whereas others are chemotactic and able to recall monocytes and macrophages at the site of infection. The chemotactic action of PC is not limited to mobilize macrophages to the site but also to activate them (Marx, 2004). The macrophages, attracted by the chemotactic action of growth factors, would be able to resolve the inflammation phase, promoting tissue remodeling due to the secretion of factors that stimulate the production of fibroblasts (such as PDGF), factors that regulate the synthesis of tissue connective components (such as TGF- $\beta$ ), and angiogenic factors (such as vascular endothelial growth factor). In summary, this therapy is believed to be based on the action of both growth factors and chemokines released by platelets that act synergistically to increase the infiltration of neutrophils and macrophages, promote angiogenesis, fibroplasia, matrix deposition, and re-epithelialization.

Moreover, as no statistically significant differences in the average values of LS at T30 were observed between PC-only- or antibiotic-only-treated quarters, it is possible to speculate that $\mathrm{PC}$ alone is able, in addition to its regenerative properties, to exert also an antibacterial effect. Bielecki et al. (2007) described that human PC in vitro inhibits the growth of Staphylococcus aureus and is also active against Escherichia coli. The $\alpha$-granules of platelets do not only contain growth factors and antimicrobial peptides, but also catecholamines, serotonin, osteonectin, von Willebrand factor, and other substances that are released in high concentrations after platelet aggregation, and many of these factors have antibacterial action. Tang et al. (2002) reported on the isolation of and the attempt to identify peptides from platelets after stimulation with thrombin and tested the in vitro antimicrobial activity of these peptides against Escherichia coli, Staphylococcus aureus, Candida albicans, and Cryptococcus neoformans. In the current study, we did not evaluate the antimicrobial effects in vitro and in vivo of $\mathrm{PC}$ using bacteriological tests, but the results of the synergic action of $\mathrm{PC}$ with antibiotic, and also those of PC alone, allow the consideration of reducing the dose of antibiotic administered or the use of PC as an alternative therapy for mastitis.

In our study, the antibiotic was administered at least 3 times, as indicated by the manufacturer data sheet. But, the obvious reduction of relapses with $\mathrm{PC}$ alone leads us to believe that the administration of PC alone could represent an adequate therapy that could allow minimization of the use of antibiotics.

Despite the limited cases, the results obtained by PC treatment for chronic mastitis are encouraging, as animals affected by chronic mastitis, generally, are culled from the herd. If our observations, although preliminary, were confirmed in a more extensive study, even cows affected by chronic mastitis could return to production after adequate treatment with PC.

The element that must always be taken into consideration is that farming is a business enterprise and, in the case of mastitis, the goal is not only clinical healing but also having the choice of treatment with the best cost-benefit ratio, maximizing the production efficiency and not focusing exclusively on treatment effectiveness (Mazzilli and Zecconi, 2010). The cost of mastitis is not only given by the qualitative-quantitative loss of milk that occurs during infection (with the consequent loss of premium quality for cells and proteins), but also by the costs resulting from the interventions required every time a case of acute mastitis turns up in the herd.

In this study, it is important to take into account the initial economic disadvantage deriving from the use of $\mathrm{PC}$ in association with antibiotic. During treatment, the cost is greater compared with the therapy with antibiotic alone but the effective recovery of the glandular tissue without the risk of further treatments due to relapse is, in our opinion, worthwhile. In the future, the absence of antibiotic residues in milk represents a good argument in favor of treatment with PC alone. Moreover, PC is a cost-effective and readily available therapeutic agent derivable from blood components and, once its efficacy is confirmed (in association with antibiotic or alone), we could hypothesize an increased interest in its application by both veterinarians and farmers.

\section{CONCLUSIONS}

Our data confirm the hypothesis that PC is involved in the healing of mammary tissue in relation to the limited rate of relapse. Nevertheless, despite these advances, it is too early to provide a complete molecular explanation for the role of the platelet in the positive 
evolution of mastitis. The wound healing involves a complex and incompletely understood array of molecular intracellular and extracellular events. It is known that platelets play a prominent and likely determinant role in the initiation and maintenance of injury healing, but further research is required to establish the optimum number of platelets to be used in PC, its efficacy in larger clinical trials, and to detect if $\mathrm{PC}$ alone could markedly influence recovery from mastitis.

\section{ACKNOWLEDGMENTS}

The authors acknowledge Regione Lombardia (Italy) for financial support through the project "PRO.ZOO."

\section{REFERENCES}

Abrahamsson, S.-O. 1997. Similar effects of recombinant human insulin-like growth factor-I and II on cellular activities in flexor tendons of young rabbits: Experimental studies in vitro. J. Orthop. Res. 15:256-262.

Akers, R. M. 2002. Lactation and the Mammary Gland. Iowa State Press, Ames.

Anitua, E., I. Andia, B. Ardanza, P. Nurden, and A. T. Nurden. 2004. Autologous platelets as a source of proteins for healing and tissue regeneration. Thromb. Haemost. 91:4-15.

Bartlett, P. C., G. Y. Miller, C. R. Anderson, and J. H. Kirk. 1990. Milk production and somatic cell count in Michigan dairy herds. J. Dairy Sci. 73:2794-2800.

Bielecki, T. M., T. S. Gazdzik, J. Arendt, T. Szczepanski, W. Król, and T. Wielkoszynski. 2007. Antibacterial effect of autologous platelet gel enriched with growth factors and other active substances. J. Bone Joint Surg. Br. 89-B:417-420.

Blecha, F. 1991. Cytokines: Applications in domestic food animals. J. Dairy Sci. 74:328-339.

Carlén, E. 2008. Genetic evaluation of clinical mastitis in dairy cattle. Doctoral Thesis. Swedish University of Agricultural Sciences, Uppsala, Sweden.

Costa, M. A., C. Wu, B. V. Pham, A. K. S. Chong, H. M. Pham, and J. Chang. 2006. Tissue engineering of flexor tendons: optimization of tenocyte proliferation using growth factor supplementation. Tissue Eng. 12:1937-1943.

Cucherat, M., M. C. Haugh, M. Gooch, and J. P. Boissel. 2000. Evidence of clinical efficacy of homeopathy. A meta-analysis of clinical trials. Eur. J. Clin. Pharmacol. 56:27-33.

Derynck, R. 1992. The physiology of transforming growth factor-alpha. Adv. Cancer Res. 58:27-52.

Erskine, R., J. Cullor, M. Schaellibaum, B. Yancey, and A. Zecconi. 2004. Research Committee Report: Bovine mastitis pathogens and trends in resistance to antibacterial drugs. Pages 400-414 in Proc. 43rd Natl. Mastitis Counc. Annu. Mtg., Charlotte, NC. Natl. Mastitis Council, Madison, WI.

Fresno, L., D. Fondevila, O. Bambo, A. Chacaltana, F. García, and A Andaluz. 2010. Effects of platelet-rich plasma on intestinal wound healing in pigs. Vet. J. 185:322-327.

Georg, R., C. Maria, A. Gisela, and C. Bianca. 2010. Autologous conditioned plasma as therapy of tendon and ligament lesions in seven horses. J. Vet. Sci. 11:173-175.
Harmon, R. J. 1994. Physiology of mastitis and factors affecting somatic cell counts. J. Dairy Sci. 77:2103-2112.

Haupt, J. L., B. P. Donnelly, and A. J. Nixon. 2006. Effects of plateletderived growth factor-BB on the metabolic function and morphologic features of equine tendon in explant culture. Am. J. Vet. Res. 67:1595-1600.

Hovi, M., and S. Roderick. 2000. Mastitis and mastitis control strategies in organic milk. Cattle Pract. 8:259-264.

IDF (International Dairy Federation). 1995. Milk: Enumeration of Somatic Cells. International

IDF Standard 148A:1-8. FIL-IDF, Brussels, Belgium.

Kehrli, M. E., Jr., J. S. Cullor, and S. C. Nickerson. 1991. Immunobiology of hematopoietic colony-stimulating factors: potential application to disease prevention in the bovine. J. Dairy Sci. 74:4399-4412.

Kim, J. H., C. Park, and H. M. Park. 2009. Curative effect of autologous platelet-rich plasma on a large cutaneous lesion in a dog. Vet. Dermatol. 20:123-126.

Krömker, V., and F. Pfannenschmidt. 2005. Zur Inzidenz klinischer Mastitiden und ihrer Therapie in Milchviehbetrieben des ökologischen Landbaus (Mastitis incidence and therapy in organic dairy farms). Pages 409-410 in Ende der Nische, Beiträge zur 8. Wissenschaftstagung Ökologischer Landbau. J, Heß and G. Rahmann, ed. Kassel University Press GmbH, Kassel, Germany..

Marx, R. E. 2004. Platelet-rich plasma: Evidence to support its use. J. Oral Maxillofac. Surg. 62:489-496.

Mazzilli, M., and A. Zecconi. 2010. Assessment of epithelial cells' immune and inflammatory response to Staphylococcus aureus when exposed to a macrolide. J. Dairy Res. 77:404-410.

National Mastitis Council. 1999. Laboratory Handbook on Bovine Mastitis. Revised ed. National Mastitis Council Inc., Madison, WI.

Rahman, M. M., M. Mazzilli, G. Pennarossa, T. A. L. Brevini, A. Zecconi, and F. Gandolfi. 2012. Chronic mastitis is associated with altered ovarian follicle development in dairy cattle. J. Dairy Sci. 95:1885-1893

Sharma, N., N. K. Singh, and M. S. Bhadwal. 2011. Relationship of somatic cell count ad mastitis: An overview. Asian-australas. J. Anim. Sci. 24:429-438.

Sheffield, L. G. 1997. Mastitis increases growth factor messenger ribonucleic acid in bovine mammary glands. J. Dairy Sci. 80:20202024

Tang, Y.-Q., M. R. Yeaman, and M. E. Selsted. 2002. Antimicrobial peptides from human platelets. Infect. Immun. 70:6524-6533.

Thomopoulos, S., F. L. Harwood, M. J. Silva, D. Amiel, and R. H. Gelberman. 2005. Effect of several growth factors on canine flexor tendon fibroblast proliferation and collagen synthesis in vitro. J. Hand Surg. Am. 30:441-447.

Weibrich, G., W. K. Kleis, W. E. Hitzler, and G. Hafner. 2005. Comparison of the platelet concentrate collection system with the plasma-rich-in-growth-factors kit to produce platelet-rich plasma: A technical report. Int. J. Oral. Max. Implants 29:118-123.

Werner, C., A. Sobiraj, and A. Sundrum. 2010. Efficacy of homeopathic and antibiotic treatment strategies in cases of mild and moderate bovine clinical mastitis. J. Dairy Res. 77:460-467.

Zhao, X., and P. Lacasse. 2008. Mammary tissue damage during bovine mastitis: Causes and control. J. Anim. Sci. 86:57-65.

Zimmermann, R., D. Arnold, E. Strasser, J. Ringwald, A. Schlegel, J Wiltfang, and R. Eckstein. 2003. Sample preparation technique and white cell content influence the detectable levels of growth factors in platelet concentrates. Vox Sang. 85:283-289. 